\title{
Paradojas de ciudadanía y conflictos de género en la política pública argentina. La Política de Salud Sexual y Procreación Responsable* Silvia Levín
}

Silvia Levín es Doctora en Ciencias SocialesFLACSO. Profesora de la Facultad de Ciencia Política y Relaciones Internacionales de la Universidad Nacional de Rosario. Investigadora del Consejo de Investigaciones de la Universidad Nacional de Rosario. Mail: silvial@arnet.com.ar

\section{resumen}

El artículo analiza el alcance del vínculo jurídico político establecido entre Estado y ciudadanas desde las garantías reconocidas en los derechos humanos sexuales y reproductivos. Utilizando un enfoque complejo, que combina diferentes dimensiones de análisis, interesa mostrar cómo y porqué las decisiones sobre la naturaleza jurídica de estos derechos y sobre su regulación política producen efectos disímiles en ese campo: desarrollo, interferencia o limitaciones de ciudadanía. Nuestra argumentación principal refiere al conflicto político que desatan esas decisiones y a los fundamentos antagónicos de las posiciones que los registran como derechos sociales de salud o como derechos individuales de libertad. En esas opciones se involucran con distinta intensidad los componentes constitutivos de la ciudadanía: la autonomía, la libertad y la igualdad. La intención es señalar que tanto el derecho como la política y la teología al fijar las "reglas de juego" en la sociedad buscan disciplinar los intereses existentes regulando el conflicto.

\section{summary}

This article analyses the scope of the judicial and political link between the State and womencitizens, observing this from the guarantees recognized in the sexual and reproductive human rights. Using a complex analysis that combines different dimensions, this article tries to show how and why the decisions about the juridical nature of these rights and about its political regulation cause dissimilar effects: develop, interference or limitation of citizenship. The core of our argumentation is the political conflict that these decisions cause and the antagonist argumentations of the positions that registries them as social health rights or as freedom individuals rights. The problem is that in these options are different forms and ways to understand the constitutive components of citizenship: autonomy, freedom and equality. Finally, we are trying to show that law, politics, and theology fix in society "the rules of the game", trying in this way to discipline existing interests and regulating conflict.

\section{palabras clave}

Ciudadanía / derechos sexuales y reproductivos / políticas públicas / conflicto político / libertad

\section{keywords}

Citizenship / sexual and reproductive rights / public policies / political conflict / liberty 


\section{Introducción ${ }^{1}$}

En las sociedades latinoamericanas actuales la democracia trasciende la idea de régimen político y es interpelada por la población, tanto en su concepción como en su modo de actuación, en la dimensión igualitaria de inclusión en la comunidad política. El trato igualitario en el ámbito público es puesto en la agenda como una de las condiciones centrales para garantizar la gobernabilidad democrática y dar contenido a las políticas públicas al asegurar el ejercicio de derechos y la construcción de ciudadanía (PNUD, 2004: 54). Si bien el contenido del reclamo de ciudadanía está puesto principalmente en el aspecto económico y social, se destaca su reivindicación legítima como mecanismo de mediación en las relaciones entre Estado y sociedad y la apuesta a sus postulados constitutivos de autonomía, igualdad y universalidad.

En este marco se inscriben las preocupaciones por las políticas de género (Jardim Pinto 2004: 266) y adquieren relevancia principal dos problemáticas: la capacidad del régimen democrático para promover la igualdad y, al mismo tiempo, su potencialidad para reconocer las diferencias que derivan de especificidades como, por ejemplo, las de las mujeres. Las llamadas nuevas teorías de la democracia, impulsadas por las corrientes feministas, discuten los distintos modelos posibles en los cuales la inclusión de nuevos actores y su nivel de participación, en particular las mujeres, sea real y no formal. Así, la democracia deliberativa, la democracia participativa y la democracia plural y radical reúnen diferentes posiciones y alternativas sobre aspectos centrales del problema. Desde esta línea de pensamiento, el desafío mayor es remover los obstáculos de la democracia liberal en la cual la diferencia se plantea sólo en el plano de las ideas, no reconociendo que está inscripta en los propios sujetos.

Conquistar la ciudadanía plena aparece como un reto de la hora actual y constituye uno de los propósitos más caros para el feminismo en las democracias modernas, porque es justamente la esfera de derechos y garantías la que otorga el anclaje jurídico y político esencial para avanzar y consolidar procesos de inclusión de sujetos sociales. El tema es qué entidad y qué alcance se le otorga a esa plataforma de derechos de manera tal que pueda sentar las bases de un modelo cívico inclusivo pero a la vez transformador, esto es, que reconozca las particularidades de género en el marco de una democracia plural (Mouffe, 1999: 101)² y sobre la base de la autonomía de la mujer como sujeto de derechos.

En efecto, si bien el problema de la autonomía en la construcción de la ciudadanía ha sido desarrollado tanto por el feminismo como por los estudiosos de la ciudadanía -fundamentalmente en el campo de la filosofía política, la sociología y la ciencia política- existe una gran reticencia a instalarlo en la agenda pública como otra de las preocupaciones actuales que inciden en las políticas de género. ${ }^{3}$ En América Latina, en particular, es uno de los aspectos que más condicionó el desarrollo pleno de la ciudadanía y comprometió severamente su alcance, no sólo en términos de ejercicio de derechos sino también de modalidades de inclusión social, política y económica de la mujer (Fleury, 2004: 62). 
La reforma constitucional de 1994 en Argentina, otorga el carácter de derechos a la sexualidad y a la reproducción al reconocer las declaraciones provenientes de instrumentos internacionales de derechos humanos como parte de su cuerpo normativo. Así, la Declaración Universal de los Derechos Humanos y la Convención Internacional sobre la Eliminación de Todas las Formas de Discriminación contra la Mujer ${ }^{4}$ expresamente prevén estos derechos, como derechos humanos, y al integrar la letra constitucional adquieren la misma jerarquía jurídica para nuestro Derecho. Si bien implica un reconocimiento formal, constituye a la vez un hecho político y un desafío para la ciudadanía.

Ese encuadre constitucional no ha sido suficiente para encauzar y completar el complejo proceso de institucionalización política que requieren los derechos en respuesta a las expectativas de inclusión que exige el modelo cívico actual. La conflictividad que reúne la temática y las disputas que genera encausarla, hace que la mayor parte de los esfuerzos estén puestos mucho más en estrategias de control político de intereses de género (aceptar, restringir o negar la libertad del cuerpo) que en los problemas inherentes a la esencia, a la "razón de ser", de estos derechos. Obviamente que esta situación encuentra sentido y significado en el devenir histórico en el cual el cuerpo de las mujeres siempre ha sido un espacio conflictivo objeto de apropiación social: sometido a discursos, prácticas médicas, reglas morales, normas, controles religiosos, disputas políticas, intereses económicos. Es "objeto de derecho" y de "derechos de otros" como si no fuera autónomo, sometido y regulado por poderes heterónomos (Ferrajoli, 2003: 11).

El tema de los derechos sexuales y reproductivos de la mujer en Argentina constituye nuestro objeto particular de interés. Nos proponemos mostrar que las limitaciones en el alcance de estos derechos son fundamentalmente de orden político y que, al restringir las herramientas jurídicas garantistas que provee el Estado de Derecho para preservar las libertades individuales, se logra controlar las capacidades decisorias de la mujer que porta su autonomía para colocarla al servicio del interés general. La inexacta consideración y regulación jurídico-política de éstos derechos como derechos sociales de salud a partir de políticas de ese campo que niegan las libertades ${ }^{5}$, cuando su "razón de ser" es habilitar libertades individuales que protegen los derechos subjetivos, es posible, como veremos mas adelante, a través de mecanismos políticos anclados en escenarios de debilidad institucional de la democracia.

Así, el Estado de Derecho pierde vigencia tanto cuando no se respeta el equilibrio entre el interés general y los intereses particulares, al imponerse arbitrariamente uno sobre otro, como cuando no se garantiza la laicidad del sistema democrático y se permite el predominio político de determinadas creencias religiosas, que afectan a toda la sociedad, a través de una construcción compleja de alianzas entre el Derecho, la Teología y la Política. Estas alianzas, por su parte, producen una suerte de "inmunidad inducida" (Espósito, 2005: 24) ${ }^{6}$ de la maternidad para poder "manejar" un objeto de interés político como lo es el cuerpo de las mujeres. A tal punto se ha distorsionado la "razón de ser" de estas facultades que el orden político, sostenido por una fuerte tradición patriarcal, ha instalado una paradoja: el 
"derecho a decidir ser madre" fue convertido, política y socialmente, en Argentina en un "deber ser madre".

La Política de gobierno sobre sexualidad y sobre reproducción, creada por Ley Nacional en el año 2002, se centró en garantizar decisiones vinculadas a la planificación familiar para procrear (oportunidad y frecuencia de nacimientos) brindando beneficios de salud pública a través de la anticoncepción reversible, pero no garantizó beneficios de ese orden para poder ejercitar decisiones voluntarias de no reproducción (anticoncepción irreversible, o atención por abortos ante embarazos accidentales o no deseados). Por tanto, quienes a pesar de su voluntad de no tener hijos, por razones personales o de salud, y de su acción anticonceptiva consecuente se embarazan, por fallas o accidentes de anticoncepción, no tienen garantías de salud pública para cumplir su decisión.

Poco tiempo después de implementarse la Política de Salud Sexual y Procreación Responsable la realidad humana forzó un acontecimiento político en Argentina con consecuencias paradójicas. El Ministerio de Salud de la Nación dispuso en el año $2005^{7}$, que todos los hospitales públicos deberán brindar salud pública a aquellas mujeres que ingresen con abortos incompletos efectuados en la clandestinidad. Esta decisión de gobierno, que tuvo como propósito detener las muertes de mujeres producidas por abortos clandestinos -que en nuestro país alcanzan a quinientos mil por año y constituye la principal causa de muerte materna-instaló sin embargo la paradoja afianzar y/o promover, implícitamente, dicha práctica para poder ser beneficiaria de la salud pública. Analicemos los alcances de la paradoja. Desde el punto de vista político, evidencia que el Estado, en este caso, no acciona a través de la política pública para atender las causas de los problemas que motivan la intervención gubernamental, demandas o necesidades de la población en contextos de pobreza ${ }^{8}$, sino que reacciona para atender las consecuencias de hechos que él mismo parece promover. Al mismo tiempo, desde el punto de vista jurídico, se pone de manifiesto que al actuar por exceso en sus atribuciones (impide a las mujeres el ejercicio de sus libertades personalísimas sexuales y reproductivas en salud) produce beneficios por defecto (la política de salud pública no garantiza prestaciones de salud plena, preventiva e integral, sino prestaciones de salud restrictivas si constata enfermedad y/o riesgo de muerte por abortos clandestinos). En consecuencia la política pública de salud promueve, paradójicamente, que las mujeres pobres se expongan a situaciones de riesgo y/o de muerte, mediante la realización de abortos incompletos e insalubres, para que el Estado les pueda brindar en esas situaciones extremas atención pública.

La causa de estas contradicciones procede, justamente, de la desnaturalización jurídica de estos derechos, del cambio de su "razón de ser", producida durante su trayectoria de gestación y regulación normativa, desde los Tratados y Convenciones Internacionales del campo de los derechos humanos hasta su regulación en el derecho interno. Obviamente no se puede desconocer que el Derecho es productor de género, al participar en la configuración del estereotipo "mujer", mediante las reglas jurídicas que reconocen o niegan derechos a las mujeres. Como tal, no agota su accionar en los aspectos normativos, sino también como discurso social y como 
legitimador de poder se impone a través de las palabras de la ley.

El encuadre jurídico de estos derechos en la esfera de las libertades individuales, y no sólo en la de los derechos sociales de salud, pretende garantizar el uso del "poder individual" en la toma de decisiones que por ser inherentes a la persona -comprometen su cuerpo- le pertenecen a la mujer y no al Estado o a la sociedad como ocurre con el tratamiento vigente. A nuestro modo de ver, este enfoque amplía la mirada sobre el problema en tanto intenta superar y corregir la visión tradicional restrictiva sobre los derechos sexuales y reproductivos, que prevalece en Argentina y en la mayoría de los países de América Latina, que los sitúa en el campo de la salud concibiéndolos jurídicamente como derechos sociales pero negando, como parte de ellos, la libertad de los derechos individuales.

La hipótesis que guía el núcleo central de nuestras argumentaciones es que la sexualidad y la reproducción hablan de la libertad del cuerpo - esencia de la libertad femenina- $\mathrm{y}$, por tanto, pertenecen al ámbito soberano de la persona, son "substratos de la persona" que corresponde sean regulados como derechos subjetivos desde la esfera de los llamados derechos personalísimos. El registro jurídico de las libertades, que preservan los derechos personalísimos, impone al poder público deberes de "no hacer", prohibiciones. Los derechos sociales, en cambio, preservan el acceso a beneficios que presuponen del Estado "el hacer", cumplir obligaciones y acciones que permitan su ejercicio. Situar los derechos sexuales y reproductivos como inherentes a los derechos sociales negando libertades, implica restringir la autonomía de la mujer condicionando su "poder individual" sobre el cuerpo, que le otorga el derecho, a decisiones políticas de los gobernantes. En definitiva, al colocar el problema en el ámbito de la política sin hacer uso de las garantías que el Derecho ha previsto para limitar el poder del Estado sobre las libertades individuales -derechos personalísimos- implica coartar la autonomía de la mujer para decidir sobre su cuerpo y someterla al arbitrio del interés general.

El nudo teórico que sustenta nuestras reflexiones refiere a los problemas que hacen a la naturaleza de los derechos de ciudadanía sexuales y reproductivos de la mujer, a partir de la revisión de las discusiones que suscita "la razón de ser" de su existencia como tales. En este debate se pretende identificar los argumentos que intentan explicar su esencia como derechos y, al mismo tiempo, presentar las consideraciones normativas diferenciadas que fundamentan su registro como derechos sociales o como derechos individuales personalísimos. ${ }^{9}$

El enfoque seleccionado responde a la complejidad analítica del objeto de estudio, se parte de la teoría de la ciudadanía para poner en diálogo luego otros aportes de la dimensión filosófica, política, jurídica, social y cultural. Desde este lugar, nos interesa mostrar cómo la decisión sobre la naturaleza de estos derechos y su regulación jurídico política produce efectos disímiles en ese campo: desarrollo, interferencia o interrupción de la construcción de ciudadanía. La noción de “inmunidad inducida" permite develar la construcción de una alianza estratégica entre los campos de saber y de poder que se propone preservar los intereses de género que prevalecen en la sociedad. En las diferentes opciones que ofrece la regulación de estos derechos se involucran con distinta intensidad los componen- 
tes constitutivos de la ciudadanía como la autonomía, la libertad y la igualdad. La intención es señalar que tanto el derecho como la política, permeados por creencias religiosas, al fijar las "reglas de juego" en la sociedad buscan disciplinar los intereses existentes regulando de esta manera el conflicto. En esa regulación lo importante es advertir la existencia o no de una combinación equilibrada entre libertad individual y seguridad jurídica para evitar así juridizaciones por exceso o por defecto. Al mismo tiempo, a partir del alcance que esas regulaciones atribuyan a estos derechos, se fundamentarán las diferentes alternativas de políticas públicas producidas desde el Estado.

\section{Dilemas de ciudadanía en democracia: las exclusiones de la inclusión}

La ciudadanía, como supuesto jurídico-político igualitario del Estado moderno, constituyó la mediación más importante en la reconstitución de la sociedad sobre la base de la integración social (Fleury, 2002: 11). Universalidad, igualdad, participación, autonomía, inclusión y libertad fueron, en general y en apretada síntesis, los componentes principales que estuvieron presentes en las distintas tradiciones conceptuales desarrolladas sobre la ciudadanía, desde el liberalismo y republicanismo hasta las producidas por autores contemporáneos, que provocaron importantes debates. Las diferencias en esas tradiciones se dan justamente por la presencia, ausencia o intensidad de cada componente en esas concepciones, o bien por el contenido asignado a cada uno en ellas.

El pensamiento feminista, se ha pronunciado sobre la temática y con una postura crítica fundamentalmente hacia el liberalismo (Pateman, 1995; Pateman, 1996; Benhabib, 2000 $)^{10}$ y el republicanismo, ha logrado incidir en la evolución del concepto e instalar nuevas perspectivas teóricas. Algunas posiciones enfatizan sobre la necesidad de recrear nuevos espacios públicos en el ámbito democrático y repensar los límites actuales de esos sistemas (Young, 1996) ${ }^{11}$; otras proponen redefinir la noción de esfera pública en la medida que las diferencias y desigualdades ocupan un espacio más formal que real (Fraser, 1996: 110); se postula también crear formas alternativas de representación donde los instrumentos de participación directa tengan mayor presencia.

La autonomía es un supuesto inherente a la definición de ciudadanía. No es posible alcanzar el status de ciudadanía plena si no se pueden ejercer las capacidades involucradas en la toma de decisiones libres (elegir, optar, establecer preferencias, concretar deseos o necesidades). Entendemos la autonomía como sinónimo de independencia decisoria que define un criterio de inclusión en la ciudadanía, tal vez el que mayor consenso ha tenido en la literatura. Al mismo tiempo que incluye también indica sus exclusiones. En países como el nuestro, la lógica de construcción de ciudadanía del Estado intervencionista estuvo mediada por vínculos de dependencia del Estado, de orden político y social, produciendo como resultado una autonomía restringida. Eran portadores de esa autonomía restringida los trabajadores formales, varones, insertos en la esfera productiva y en consecuencia poseedores de derechos de ciudadanía. El resto de la población estaba excluida del status de ciudadanía, por 
no alcanzar las condiciones de autonomía exigidas por el modelo de organización social imperante, y considerada objeto de tutela y protección social del Estado.

En este registro se ubicó a la mujer, justificándose su exclusión en el criterio de ausencia de autonomía y sometida, a los otros parámetros vigentes. ${ }^{12}$ La ciudadanía de la mujer nace bajo condición de tutela del Estado, sin posibilidades de autodeterminarse, de decidir sobre sí misma. Se han producido avances en diversas esferas de derechos de ciudadanía - civiles, políticos y sociales- pero no son suficientes para garantizar el desarrollo pleno de las capacidades decisorias de la mujer.

En las luchas por el reconocimiento de las diferencias se encuentra presente una articulación compleja entre reivindicaciones que dependen de la igualdad y reivindicaciones que pertenecen a la esfera de la libertad. La manera de canalizar estas nuevas expresiones en el espacio político es a partir de lo que se ha denominado "democracia plural y radical"13, desde donde se articula un modelo de ciudadanía democrática plural. Con esta noción, se trata de definir nuevos usos y nuevas significaciones para las ideas de libertad e igualdad. La ciudadanía es concebida como identidad política que se crea a partir de la identificación con la comunidad pública, con la res-pública. Esa identidad política, implica una forma de identificación para Mouffe y no simplemente un status legal. No pone todo el énfasis en los derechos, sino que avanza desde ese reconocimiento hasta reunir la ciudadanía con dimensiones políticas, culturales y simbólicas a las que refiere la identidad. La identidad política común involucra a un conjunto de personas que aceptan el sometimiento a reglas que prescribe la comunidad política pública: un conjunto de valores ético-políticos. Se trata de una concepción de ciudadanía que apunta a la construcción e identificación con una democracia radical en la cual los principios de libertad e igualdad tengan un significado común.

Este cambio implica conflictos propios de la lucha por la extensión de la democracia. El problema del enfoque liberal, según Mouffe, es que ignora los límites que impone la extensión del pluralismo debido a que algunos de los derechos existentes se han constituido mediante la exclusión o subordinación de los derechos de otros sujetos sociales. Para fundar una nueva ciudadanía y reconocer nuevos derechos es preciso primero "deconstruir esas identidades". Desde esta perspectiva se reformula la relación público/privado. En cuanto al género, por ejemplo, el dominio público de la ciudadanía moderna se basó en la negación de la participación de las mujeres. Esta exclusión fue considerada indispensable para sostener la generalidad y la universalidad de la esfera pública. En este registro, la distinción público/privado primordial para la afirmación de la libertad individual, determinó la identificación de lo privado con lo doméstico y subordinó a las mujeres.

El status de ciudadanía, así concebido, confiere legitimidad para el ejercicio del poder político y, al mismo tiempo, neutraliza las diferencias propias de los distintos actores sociales colectivos para enfatizar la figura del sujeto individual, portador de derechos y deberes que garantizan su inclusión en sociedad. Por tanto, la ciudadanía define los criterios de inclusión en la comunidad política y de dere- 
chos, generalmente producto del consenso, que son al mismo tiempo aquellos que sancionan las normas de exclusión (Mouffe, 1999: 101).

La reproducción y la sexualidad integran la lista de las exclusiones de la inclusión de ciudadanía plena de la mujer en nuestro sistema democrático actual. Como analizaremos en las páginas que siguen este problema nos permite ilustrar, a partir de la naturaleza y alcance asignado a estos derechos, cómo y porqué se construyen las exclusiones de ciudadanía y cuáles son las consecuencias de la negación de autonomía plena para las mujeres en la mayoría de los países de América Latina.

\section{Los derechos sexuales y reproductivos entran en escena}

Instalar la problemática de la sexualidad y la reproducción en nuestro país, tanto como tema de Estado o como concerniente a la esfera de los derechos individuales, resultó ser un proceso sumamente conflictivo y reticente a la voluntad pública y a la de ciertos sectores sociales de corte conservador. El ritmo de desenvolvimiento de ese proceso, que jurídicamente involucra atribuciones públicas del Estado y atribuciones privadas de los ciudadanos, no ha sido equilibrado en esas dos esferas. A pesar de la resonancia internacional de la salud sexual y reproductiva en la década de los $80^{\circ}$, en nuestro país ha permanecido silenciada hasta mediados de los años $90^{\circ}$, en que adquiere visibilidad pública al mismo tiempo que se incorpora a la agenda de Estado.

El Estado argentino, hasta mediados del siglo XX, reguló voluntades y conductas de sus ciudadanos en desmedro de sus libertades individuales, mediante un uso ilimitado de poder amparado en el interés general, a través de instrumentos normativos y prácticas políticas. En este sentido, sus acciones fueron eminentemente represivas acompañadas de un importante consenso de sectores conservadores ${ }^{14} \mathrm{de}$ nuestra sociedad que bregaban por políticas "promaternalistas" (Barrancos, 2002: 17). ${ }^{15}$ Desde los años 70 ' hasta mediados de los $80^{\prime}$, se invocaron razones de Estado, como la necesidad de poblar el país, para fundamentar esas decisiones públicas en materia de políticas de población.

Desde las corrientes feministas se comienza a promover la visión de la mujer como sujeto de derechos. En esa línea, se concibe a los derechos sexuales y a los derechos reproductivos como derechos humanos. Por otra parte, la sexualidad es definida como dimensión ligada a la plenitud de la salud humana. En el discurso se vinculan también los derechos sexuales con los derechos reproductivos, pero respetando la autonomía propia de cada esfera de atribuciones y preservando la decisión de ser ejercidos de manera conjunta o independiente en el ámbito de las libertades individuales.

Otra vertiente importante de pensamiento en la temática, aunque con motivaciones e intereses diferentes, fue la proveniente del campo de la salud pública. Desde ese espacio se definió conceptualmente a la salud reproductiva y se adoptaron posiciones críticas tendientes a orientar e incidir en el contenido que deberían tener las políticas públicas y/o programas sociales para garantizar la salud sexual y reproductiva de la población. Efectivamente, desde fines de los 90' la producción intelectual en salud pública ha incidido positivamente en las políticas de Estado. ${ }^{16}$ 
El advenimiento de la democracia en 1983 produce el primer giro importante en la temática en la medida que las libertades individuales comienzan a ser objeto de preocupación y regulación garantista por parte del Estado. ${ }^{17}$

Su consideración como derechos humanos permitió asignarles eficacia jurídica, validez universal, fundamento ético y exigir un particular tratamiento. No obstante, este significativo impulso tiene limitaciones tanto teóricas como jurídicas y políticas. En efecto, los Tratados y Convenciones Internacionales gestores del proceso de reconocimiento universal de los derechos de la mujer, fundamentan la sexualidad y la reproducción como facultades inherentes a la libertad pero recomiendan a los Estados Parte su implementación a partir de políticas sociales de salud. El interés jurídicamente protegido por estos derechos es la salud y se invoca la libertad como fundamento para actuar y decidir pero no se la garantiza. Enuncian una noción integral de salud reproductiva y salud sexual, que intenta establecer el horizonte de los derechos sexuales y reproductivos inscriptos en el estado general de bienestar físico, mental, social y la capacidad de disfrutar una vida sexual satisfactoria y sin riesgos, y aluden, al mismo tiempo, a la libertad para decidir.

Del análisis específico de estas disposiciones normativas se desprenden dos situaciones que ponen en evidencia una tensión entre el espíritu general de orden valorativo, que intenta trasmitir el discurso de esas normas, y el objetivo particular de orden político que surge del contenido de las mismas. Así, por un lado, no se contemplan definiciones específicas de salud reproductiva ni de salud sexual. Los derechos y los beneficios que compromete la salud pública sólo prevén condiciones para reproducir pero no para no reproducir, por ejemplo cuando los embarazos no deseados se producen por fallas o accidentes de anticoncepción. Es decir, la decisión de no reproducir no es considerada saludable en el ámbito público.

De la misma manera se protege la salud sexual para procrear, pero no se mencionan otras capacidades que hacen a la esencia de la sexualidad como es el deseo que se puede manifestar sólo si hay garantías de libertad sexual. Por otro lado, tampoco estos derechos garantizan la libertad reproductiva para decidir, sino que la cuota de libertad individual permitida se orienta de manera restrictiva a las opciones que involucran solamente decisiones sexuales para procrear con racionalidad planificadora-oportunidad y frecuencia de nacimientos- pero no para no procrear. Si la decisión de no reproducir hubiera sido aceptada jurídica y políticamente en el año 2002, como un acto de voluntad emanado del ejercicio de la libertad individual de la mujer sobre su cuerpo, la salud pública debería haber garantizado anticoncepción irreversible y abortos seguros en caso de embarazos no deseados o producidos por fallas de planificación familiar. Sin embargo, la autodeterminación de la voluntad individual es cercenada por el orden colectivo a través de sanciones penales y omisiones de políticas de Estado en los casos de aborto. Por otra parte, la anticoncepción irreversible (anticoncepción quirúrgica) recién constituyó un derecho en el año 2006 en todo el país. ${ }^{18}$

Esta posición conceptual y política de la problemática es coherente con la consideración y regulación jurídica que muestran las normas vigentes relativas al registro de los derechos humanos. En ese registro sólo se alude a la libertad como 
fundamento valorativo de estos derechos pero políticamente son regulados como derechos sociales -derechos humanos de segunda generación- y se coartan las libertades individuales que preservan los derechos de primera generación. Libertades que, por ser consideradas inherentes a la condición humana y por tanto anteriores y superiores al poder del Estado, limitan la competencia del poder público para interferir en su ejercicio y pleno goce de las mismas. En nuestra perspectiva, los derechos reproductivos encuentran su fundamento en el reconocimiento a hombres y mujeres de la libertad reproductiva del cuerpo, esto es ejercer con independencia decisoria la capacidad reproductiva y/o no reproductiva como opciones electivas sin discriminación, coerción y violencia. Asimismo el acceso a los servicios educativos y a la información, incorporan recursos culturales y simbólicos que inciden en la calidad del contenido de los derechos reproductivos produciendo efectos significativos en los mecanismos de uso de los derechos.

La noción de derechos sexuales, invoca la libertad sexual como la capacidad de expresar el deseo, de disfrutar de una vida sexual placentera, sin riesgos ni coacciones, con posibilidad de tomar decisiones y de ejercer opciones. El contenido de estos derechos exige políticas que otorguen beneficios capaces de garantizar la sexualidad como deseo de ejercicio de libertad y no sólo como condición reproductiva. En este sentido, se requiere de la planificación familiar, el control voluntario de la procreación, la prevención de enfermedades de transmisión sexual, la maternidad sin riesgos, prevención de embarazos adolescentes y servicios de salud pública para abortos seguros. Asimismo, compromete los servicios educativos e informativos del Estado que tendrán por misión formar, informar, asesorar, sobre la problemática reforzando aspectos culturales y simbólicos de ciudadanos y ciudadanas.

Los derechos sexuales y reproductivos que regulan las políticas públicas no garantizan beneficios acordes a las necesidades y expectativas ciudadanas de la mujer, en tanto al recibir un tratamiento jurídico desnaturalizado de los intereses que protegen siguen priorizando la voluntad colectiva, que promueve la procreación, en desmedro de la autonomía individual que preserva la independencia decisoria de la mujer.

En síntesis, las posibilidades jurídicas para garantizar tales derechos están mediadas por factores políticos, culturales, simbólicos y sociales. En nuestro país, los derechos individuales de sexualidad y reproducción si bien fueron valorados constitucionalmente como libertades y demandados políticamente con tal carácter por los sectores progresistas, solo lograron ser aceptados por la mayoría de la sociedad, luego de un arduo conflicto político entre sectores católicos conservadores y sectores progresistas ${ }^{19}$, como derechos sociales de salud y así fueron definidos por legisladores y legisladoras en el año 2002 con la sanción de la Ley Nacional que crea la Política Nacional de Salud Sexual y Procreación Responsable.

Los avances legislativos y político ${ }^{20}$ siguen produciéndose con carácter conflictivo, con la finalidad de superar el déficit de libertad. El registro de estos derechos en el campo de la salud buscó, en su momento, lograr el equilibrio posible, aunque no el deseable, entre el interés general y el interés particular en la medida que, 
aunque sean tratados como tales y no garanticen la autonomía ciudadana, la mujer logró tener reconocimiento como sujeto de derechos ${ }^{21} \mathrm{y}$ el Estado asumió por primera vez responsabilidades políticas en la materia.

\section{Entre el discurso y la realidad de los derechos sexuales y reproductivos}

El tratamiento jurídico que se le ha dado a la problemática de la sexualidad y de la reproducción nos sitúa en el discurso de los derechos y en la realidad de las políticas que los regulan y dan contenido.

Los derechos individuales constituyen el referente fundamental para discutir la razón de ser de los derechos sexuales y los derechos reproductivos y a la vez ordenarlos jurídicamente. Al decir de Habermas (1999: 79), son el "estuche protector" de los intereses individuales. Intereses y sujetos son procesados jurídicamente a fin de producir su regulación social. Pero esos intereses no constituyen abstracciones, sino que intrínsecamente reúnen conflictos reales que se exteriorizan en la presión de los grupos para instaurar sus demandas en "las reglas de juego" del derecho y ver protegidas sus necesidades.

El objeto de tutela de los derechos individuales es fundamentalmente la libertad en el marco del orden jurídico. Los derechos subjetivos -como facultades de la persona que la hacen apta para poseer o hacer algo justamente (Villey, 1964: 97)resultan ser la figura jurídica más afín a la esencia de los derechos humanos.

Los derechos sexuales y los derechos reproductivos no son definidos con precisión en los Tratados y/o Convenciones Internacionales. No hay una referencia expresa, aunque sí implícita, a su objeto de protección legal sino, en todo caso, se hace una alusión a facultades que atribuyen a partir de la enunciación de prácticas protegidas o bien beneficios que los Estados Parte se comprometen a garantizar en el ámbito de la salud. Es decir, las normas se preocupan por delimitar lo permitido y por tanto excluir lo prohibido, en el ejercicio de la sexualidad y la reproducción, pero no por definirlos como derechos en sí mismos. ${ }^{22}$

Una segunda consideración importante en nuestro cuerpo argumental es que la sexualidad casi no tiene presencia autónoma en el ordenamiento normativo sino asociada a la reproducción. La separación de la esfera de la sexualidad de la esfera de la reproducción ha sido uno de los logros del feminismo al instalar la visión de la mujer como sujeto de derechos y al inscribir el tema de la autonomía en el debate sobre la dicotomía público/privado. Es la posición de la mujer en la comunidad política como sujeto de derechos lo que se pone en riesgo con situaciones ambiguas.

La Constitución Nacional recoge, a través de las disposiciones de derechos humanos, la voluntad universal de consolidar el status jurídico de ciudadanía de la mujer superando todo tipo de discriminaciones y estereotipos provenientes del género. No reconocer la autonomía de esferas supone, sin embargo, exactamente lo contrario: negar la libertad sexual y a la vez condicionar la libertad reproductiva. ¿Nos encontramos, entonces, frente a una paradoja jurídica? La aspiración general del ordenamiento vigente, según se deduce de la letra de las normas, no se condice con el tratamiento de algunas situaciones particulares como la que nos 
ocupa. El valor de la libertad, a pesar de las proclamas discursivas sucesivas en las disposiciones mencionadas, no logra legitimar la sexualidad y la reproducción para otorgar autonomía plena. Si esto es así ¿la Ley Suprema de la Nación constituye a la mujer en sujeto de derechos sobre la base de sus intereses particulares o la constituye en sujeto de derechos de otros intereses?

El análisis de la ubicación jurídica de estos derechos, que surge en el intento de buscar la base de legitimación más apropiada para su desarrollo, despeja algunas dudas acerca de la cuestión. Quienes los ubican en el campo de la salud, atendiendo a su protección integral, encuentran sus argumentos en acciones y prácticas que, aunque provengan de distintas disciplinas, tienen por objeto principal producir efectos en relación con la enfermedad, ya sea de manera preventiva, curativa o como control. Incluso concibiendo a la salud en el marco del bienestar general, y no como mero tratamiento médico, esta argumentación lleva a considerar estos derechos como "opciones terapéuticas" (Lema Añon, 1999: 291). ${ }^{23}$ En estas opciones las manifestaciones implícitas de deseos, presentes en el derecho a la reproducción y en el derecho a la sexualidad y próximas a la esfera de las libertades, suelen quedar desvalorizadas ante la imperiosa necesidad terapéutica. Entre las razones que sostienen estas posiciones algunas aceptan el sacrificio de los derechos de la mujer -integridad, autonomía, libertad del cuerpo y la persona- en salvaguarda de los derechos de otros (la familia, la reproducción de la especie, la vida del embrión, el derecho de los hijos, etc.).

En América Latina, que fundamenta estos derechos en la salud pero sin respetar las libertades individuales, la objetividad de la realidad social instaló un escenario que permite incorporar matices a esta posición que, aunque no logren modificar el nudo de la argumentación que se discute, contribuyen sin embargo a mostrar cómo las mediaciones -sociales, políticas y culturales- atraviesan las lógicas jurídicas. En efecto, existe un consenso - político, social y científico- en considerar la temática como parte la salud. No fueron exclusivamente razones de Estado las que colocan los derechos sexuales y reproductivos en la agenda pública de salud ni tampoco las que fundamentan tal decisión, sino que también un sector de la sociedad, como señalamos, se compromete con esa posición.

La producción de conocimiento científico desarrollada en los últimos tiempos sobre este tema en nuestro país, provenientes de las instituciones más diversas ${ }^{24}$, ha contribuido a instalar el problema en la agenda pública, mostrar su dimensión política y social -mediante la elaboración de diagnósticos e informes de situación sobre la base de información estadística producida por organismos oficiales- y exponer los argumentos que justifican su urgente tratamiento. Existe un marcado consenso en el campo científico y social, que convive sin dudas con el disenso, sobre la trascendencia del problema y su impacto en la vida de la población, en particular la de menores recursos. Los programas y políticas sociales del Estado intentan disminuir el número de embarazos no deseados y abortos clandestinos, detectar y tratar el cáncer cervical y de mama, mejorar la atención prenatal y postnatal, reducir el riesgo reproductivo en las adolescentes, prevenir el sida y las enfermedades de transmisión sexual. 
Por otra parte, también el tratamiento jurídico que recibe la salud -objeto de protección legal- como derecho social exige consideraciones particulares. Se trata de una esfera de derechos cuya realización no depende de un problema filosófico, ni jurídico, ni moral sino de un cierto desarrollo de la sociedad (Bobbio, 1993a). Es decir que la garantía y protección de los derechos sociales es tanto un asunto político como una cuestión jurídica, en tanto la asignación del gasto social del Estado no depende sólo del reconocimiento que se haga de los derechos sociales, sino fundamentalmente de decisiones políticas de los gobernantes (Yturbe, 1995: 161).

En esta regulación el derecho ha actuado tanto por defecto como por exceso. Por defecto, por no haber garantizado la laicidad del Estado impidiendo las interferencias de poder de las creencias católicas sobre las decisiones públicas ${ }^{25}$ para proteger los derechos individuales de la mujer. Por exceso, al utilizar el registro jurídico de los derechos sociales de salud para acentuar la tutela de valores que logran garantizar fines sociales, como los relativos a la familia y a la procreación desconociendo la autonomía decisoria de la mujer.

La esencia de estos derechos también pone en tensión las ideas de justicia social -igualdad social-y justicia política-igualdad de libertades (Heller, 1989: 207)- hasta lograr un entendimiento relacional. Si se alcanzan mayores libertades, aumentan las posibilidades de que mejoren las condiciones de vida de ciudadanas y ciudadanos. Las exigencias de justicia social tienen una fuerte implicancia política. Por otra parte, cuanto mejores sean las condiciones de vida, mayores serán las exigencias de libertad e igualdad. No obstante ello (Rawls, 1996), la igualdad social puede alcanzarse sin que existan libertades -como ha ocurrido en sistemas autoritarios- pero la justicia política tiene prioridad sobre cualquier otro tipo de justicia (Heller, 1989: 207).

Esto es así en tanto no se entiende la libertad como un "estado" al cual se aspira alcanzar, sino como la "actividad" capaz de hacer realidad las oportunidades que ofrece la vida o que uno busca en la vida (Dahrendorf, 1990). El "aspecto constitutivo" de la libertad, ausencia de coerción, apela indefectiblemente al "aspecto instrumental" de la libertad, capacidad de obrar por cuenta propia, para adquirir existencia y realidad. El derecho a decidir libre y responsablemente no tener hijos en América Latina no puede adquirir realidad porque no se dispone del aspecto constitutivo ni instrumental de la libertad individual. Lo paradójico de esta situación es que desde la cuna normativa de la "no discriminación" a nivel de derechos humanos, como lo es la Convención sobre la Eliminación de Todas las Formas de Discriminación contra la Mujer (CEDAW), se discrimina entre hombres y mujeres que quieren tener hijos y los que no quieren tener hijos, negándoles la igualdad de oportunidades y de trato tanto en el plano normativo como en el de las políticas de Estado. En efecto, el avance conceptual que promete la Convención se desvanece ante las condiciones instrumentales que, bajo la forma de "medidas" que deben adoptar los Estados Parte, proporciona para el ejercicio de los derechos sexuales y reproductivos al ubicarlos en el campo de la salud pero negando la libertad para decidir. ${ }^{26}$ 
Quienes los conciben como derechos personalísimos entienden a los derechos sexuales y a los derechos reproductivos como autodeterminaciones físicas que hacen a la libertad de la persona. Los derechos personalísimos, que prevé nuestro ordenamiento jurídico, se preocupan por abrir un camino capaz de garantizar la libre y necesaria expansión individual. Son derechos que nacen con el sujeto, son inherentes a la persona, inseparables de ella. Adquieren existencia a partir del momento en que se es persona. Otorgan facultades que el hombre o la mujer ejercen en relación a su vida, a su honor, a su cuerpo, su identidad, su libertad, su intimidad, su imagen. Contemplan aquellos aspectos constitutivos de su individualidad, y como tal definen al mismo tiempo su autonomía. En cuanto son reglas sociales indicativas del "deber ser" se ocupan del hombre y de la mujer y, en consecuencia, de aquéllas bases que hacen a su propia naturaleza: la vida y la libertad (Cifuentes, 1995: 148).

En cuanto a su naturaleza, son considerados derechos subjetivos. Protegen el valor de la libertad y la autonomía. Es decir, la norma coloca al individuo en posición de defender sus intereses, de exigir a los demás, en el ámbito de las relaciones sociales, un especial comportamiento -ya sea acción u omisión-y le confiere las defensas necesarias para su preservación. Asimismo le garantizan el "señorío" sobre su cuerpo y su mente. Es ese señorío de la voluntad el que permite ejercitar facultades y decisiones sobre la propia vida, la libertad, el cuerpo. Esa potestad no es ilimitada, el Estado se ocupa de marcar las "fronteras" entre las atribuciones privadas y el interés general. Esas fronteras van a expresar los parámetros de convivencia aceptados por la comunidad -inclusiones/exclusiones- como constitutivos del orden social vigente.

Desde la esfera de la libertad y la autonomía se funda tanto la sexualidad como la reproducción de la mujer, y el cuerpo es el objeto de protección legal en tanto asunto que hace a la libertad femenina. En esta argumentación la libertad femenina es directa o indirectamente la libertad del cuerpo. Esa libertad es la que amenaza el viejo orden familiar, en el cual la mujer es utilizada como medio para fines que no son suyos (Ferrajoli, 2003: 15). Los conceptos de libertad negativa y libertad positiva (Berlin, 1988; Bobbio, 1993b) son los recursos teóricos principales alrededor de los cuales se construye, en nuestra visión, el discurso argumental en torno al sentido y significado de los derechos sexuales y reproductivos. La palabra libertad en su sentido positivo expresa el deseo del individuo de ser su propio dueño, que su vida y sus decisiones dependan de sí mismo y no estén sometidas a actos de voluntad de otros sujetos. Supone tomar determinaciones sin condicionamientos externos. Es lo que denominamos autodeterminación o bien autonomía decisoria. La libertad negativa, por su parte, alude a la opción de obrar o no obrar sin ser obligado a ello o sin que otros sujetos lo impidan. Es la libertad como ausencia de impedimento o libertad como ausencia de constricción. Es decir que comprende tanto la libertad de hacer como la de no hacer.

La libertad femenina es una libertad positiva, es decir otorga a la mujer la posibilidad de autodeterminarse, de expresar su propia voluntad. Pero esa libertad es positiva en la medida en que previamente se le reconozca también la libertad 
negativa, esto es la posibilidad de obrar o no obrar sin ser obligada a ello o sin que se lo impidan otros sujetos. La autodeterminación de procrear (maternidad) es una libertad positiva. Antes que una libertad de abortar (libertad positiva) implica una liberación de la servidumbre personal (libertad negativa) a la que se ve sometida la mujer cuando se siente en la obligación de ser madre y en la instrumentalización de su cuerpo para lograr una finalidad que no es la suya, que no la ha querido ni decidido. En ese caso el fin es social, de perpetuación de la especie, en la que el ser humano es tratado como un objeto antes que como un sujeto de derecho y de derechos (Ferrajoli, 2003: 15). Por otra parte, la libertad sexual es una libertad positiva como punto de partida, que a su vez involucra la libertad negativa. Así, la anticoncepción o la planificación familiar son libertades negativas que tienen que fundarse en la autonomía, libertad positiva, para que la sexualidad sea efectivamente una actividad en ejercicio de la libertad del cuerpo.

Cuando se examinan derechos se ven intereses, sujetos implicados, valores en disputa, comportamientos disciplinados. Sin embargo cuesta mucho aún ver y dar a la mujer una existencia separada de los "otros". La libertad femenina, al decir de Ferrajoli, es directa o indirectamente la libertad del cuerpo. Es este valor el que porta la autonomía y el que funda la ciudadanía como identidad política. La mujer no puede subordinar la autonomía a otros valores, ni siquiera al de salud, porque en cada acto de sesión entrega partes de su libertad. En todo caso sí podemos aspirar a una articulación equilibrada de valores. Los derechos personalísimos desafían a esa labor.

\section{El conflicto por la libertad y el consenso de la "inmunidad"}

El proceso de transformación de los derechos de las mujeres en la región ha recorrido un camino complejo que lo diferencia de otras evoluciones de derechos de ciudadanía relativas a otros sujetos sociales. En efecto, instituir derechos de sexualidad y de reproducción no involucra sólo un procedimiento político y jurídico de consagrar voluntades y establecer facultades, sino que interpela y remueve el sistema de género dominante en las sociedades actuales.

La pretensión de libertad del cuerpo, aspiración máxima del movimiento feminista tras estos derechos que "desordenan" el orden patriarcal, instala en sí misma un conflicto de ciudadanía porque busca constituir una identidad política propia en un mundo masculino sostenido por creencias católicas conservadoras. En ese mundo, lo masculino es lo público y lo público es político. Lo femenino, en cambio, es privado y lo privado es domesticidad maternal, no es asunto político ni público y está instituido de un "aura sacra". Por tanto, lo que intentan defender las mujeres -la libertad de decidir- es justamente lo que pretende combatir el orden patriarcal. Estas son las razones fundamentales que pugnan entre el "desorden" y el "orden".

Pero ese orden, aunque prevalezca, no es homogéneo ni abstracto ni estático. Las reivindicaciones de ciudadanía de las mujeres, las que impulsan la apertura de cambio, tienen anclaje en algunos sectores sociales que toman sus demandas e intentan traducirlas en decisiones políticas. Así, sectores del ámbito político, legis- 
lativo, ejecutivo y judicial se comportan como protagonistas del proceso de transformación actuando como interlocutores y mediadores entre Estado y sociedad.

El conflicto por la libertad arrastra también las reivindicaciones por la igualdad de género y por la justicia social. La equidad de género, entonces -con el rostro de libertad e igualdad- atravesó partidos, grupos e ideologías y unificó a la mayoría de las legisladoras y a algunos legisladores por su esencia de humanidad. ${ }^{27} \mathrm{El} \mathrm{mis-}$ mo clima invadió buena parte de la sociedad y las mujeres - de distinta condición social, profesional, política y laboral- desarrollaron -y desarrollan aún- una verdadera labor militante. La sexualidad y la reproducción no son reclamos por sólo dos esferas de derechos sino que instalan en la sociedad la necesidad y la lucha por una identidad política de ciudadanía plena. Un verdadero "desorden" del "orden" establecido. No se trata, entonces, de cualquier conflicto sino de un conflicto de carácter político porque pone en riesgo la unidad y la estabilidad social.

Por otro lado, las oposiciones católicas conservadoras del tejido social se hacían oír en el espacio público y en el Congreso de la Nación en la forma y en el carácter más diverso. Son las que transportan los sujetos en la dinámica de las relaciones sociales cotidianas y que interceden y dificultan el reconocimiento y el ejercicio de los derechos sexuales y reproductivos de la mujer.

Los medios de comunicación, la Justicia, asociaciones y sociedades profesionales diversas, organismos de derechos humanos, Centros de Estudio e Investigación, representantes de organismos internacionales, Iglesia Católica ${ }^{28}$ y demás instituciones y creencias religiosas, entre otras, formaban la opinión pública y ejercían influencia y control en los acontecimientos y en las decisiones.

El primer síntoma del conflicto es la dificultad de ese "orden" político y social de aceptar a la mujer como "persona" sujeto de derechos. Es decir, como sujeto individual de ciudadanía "que tiene derecho a tener derechos", por el sólo hecho de ser persona. Fundar la ciudadanía en la calidad de "persona" es reconocer la identidad política de la mujer como adquisición pública constitutiva de libertad. Este conflicto también estuvo presente en el ámbito internacional a la hora de consensuar las normas constitutivas del derecho internacional de los derechos humanos en estos temas. El consenso político universal acordó reconocer a la mujer como sujeto de derechos a la salud sexual y a la salud reproductiva en el marco de la planificación familiar. La reconoce ciudadana pero no en plenitud, tiene derecho a tener sólo algunos derechos de libertad individual pero no la libertad del cuerpo. La libertad del cuerpo es de pertenencia social, no individual, fundamento de reproducción de la especie y del desarrollo social de base familiar.

El consenso político democrático logra algunos beneficios como el reconocimiento de estos derechos en el campo de la salud. Pero, no obstante ello, la lucha por la libertad del cuerpo sigue su curso y seguramente perdurará hasta concretarse porque constituye un acto de justicia no de mera voluntad. Los síntomas concretos de esa continuidad son los reclamos actuales del movimiento feminista por la legalización del aborto, la despenalización del aborto, salud pública postaborto, anticoncepción quirúrgica, etc. Mientras la comunidad organizada no reconozca que las mujeres "tienen derecho al derecho de libertad del cuerpo" está 
sosteniendo un vínculo político de ciudadanía restringida por el género. Esta es la asignatura pendiente.

La racionalidad del conflicto permite implementar procedimientos para manejar las controversias y constituir un orden que sirva como "refugio" y como orientación social. El reconocimiento de "enemigos justos" y no de "enemigos absolutos" supone asumir de manera recíproca entre rivales que "el otro" puede tener legítimamente una posición diferente (Schmitt, 1984: 32).

Cuando el conflicto transcurre en condiciones políticas propicias para su desenvolvimiento, no para su desaparición, puede alcanzar el consenso. Desde este lugar, el "enemigo político" no es "enemigo absoluto", aquel con quien no se tiene nada en común, sino aquel con quien se comparten un conjunto de normas jurídicas de reconocimiento recíproco. El reconocimiento recíproco de ciudadanos y ciudadanas como personas, sujetos "que tienen derecho a tener derechos", constituye el consensus iuris (Arendt, 1987: 110). Este consenso hace posible la pluralidad y la contingencia en sociedad.

Todo conflicto es político cuando, además de trascender la esfera privada, se encuentra en juego el reconocimiento identitario o la definición de fines colectivos y mantiene una referencia al consensus iuris. Si no se logra instalar en el conflicto el reconocimiento del consensus iuris, la contienda se transforma en una guerra o deriva en represión. Este consenso constituye un mecanismo propio de la dinámica política, según la cual el "enemigo" es aquel con el cual se tiene que convivir. Por tanto, a través del consensus iuris no se busca eliminar "al otro" sino constituirlo en "adepto"(Arendt, 1987: 115).

En este marco el consenso político alcanzado en el plano de los Derechos Humanos, el derecho humano a la planificación familiar como derecho social, expresa mucho más la voluntad política de preservar la unidad social que la voluntad jurídica de reconocer personas con derecho a tener derechos. Consideramos a ese consenso político, plasmado en Argentina en la Reforma Constitucional de 1994, como el punto de inicio de un proceso de formación del consensus iuris. El derecho interno, a través de disposiciones de orden político, completa la construcción de esos derechos al establecer el contenido de ese reconocimiento en el campo de la salud. La Ley de Salud Sexual y Procreación Responsable, entonces, coronó el proceso de formación del consensus iuris determinando desde el ámbito de la política de salud pública el contenido y alcance de ese reconocimiento. Este consensus iuris es el que rige en toda América Latina. No obstante el avance producido, la realidad social y política de las mujeres siguió interpelando desde el lugar de la libertad a ese consensus iuris consagrado como "refugio" en la salud. Como respuesta se lograron, con posterioridad al año 2002, garantías de salud pública en la atención post-aborto y en la anticoncepción quirúrgica que la Ley no reconocía como derecho de salud.

Si esto es así, nuestros interrogantes son los siguientes: ¿el consensus iuris ha logrado el cometido de mediación entre derecho y política en América Latina? O dicho de otra manera, ¿han logrado las mujeres el reconocimiento "del derecho a tener derechos" como identidad política de ciudadanía o sólo como condición 
ampliada de ciudadanía? Es obvio que uno u otro reconocimiento establece relaciones de poder disímiles con "el otro" (orden dominante) en el conflicto.

Para comprender el conflicto es necesario conocer la esencia del pensamiento que sustentan los principios de unos y otros contrincantes: los que se mueven en el "orden" dominante y los que provocan su "desorden". En la medida en que intentemos establecer qué se busca defender y qué se busca combatir, también sabremos por qué se defiende y por qué se combate en cada dirección.

El catolicismo conservador ${ }^{29}$, ve en las facultades sexuales y reproductivas una amenaza a los parámetros de organización y regulación natural de la vida y la sociedad que sostienen su doctrina y su magisterio. En ese "orden", la familia "constituye el lugar natural y el instrumento más efectivo de humanización y personalización de la sociedad: colabora de manera eficaz y profunda con la construcción del mundo, haciendo posible una vida propiamente humana, en particular trasmitiendo las virtudes y los valores". ${ }^{30}$ Está determinada naturalmente a la indisolubilidad, no por voluntad individual, sino por designio divino. Al ser "el santuario de la vida", anida en ella la base de todos los derechos humanos: "el derecho a la vida". Es la "iglesia doméstica" que anuncia la palabra de Dios, santuario donde se edifica la santidad y desde donde la iglesia y el mundo pueden ser santificados. ${ }^{31}$ La realidad del amor natural de la familia es elevada a la dimensión de sacramento divino con el matrimonio cristiano. De allí que éste sea un derecho natural e indisoluble.

En ese santuario doméstico la vocación de la mujer es la "de madre, defensora de la vida y educadora del hogar". Las mujeres han sido durante siglos "el ángel custodio del alma cristiana del continente". ${ }^{32}$ Son quienes dan y defienden la vida, por tanto la sexualidad es condición natural de la identidad sexual. La procreación es una actividad natural que realiza al matrimonio en el amor y trasciende a Dios en su voluntad. El deseo es pecado.

La libertad, por sí misma, sin distinción del bien y del mal de origen divino, no encuentra una realización verdadera, es libertinaje y destruye al hombre y a la sociedad. La libertad "no tiene un origen absoluto e incondicionado en sí misma, sino en la existencia en la que se encuentra y para la cual representa, al mismo tiempo, un límite y una posibilidad. Es la libertad de una criatura, una libertad donada, que se ha de acoger como un germen y hacer madurar con responsabilidad". ${ }^{33}$ Esto significa que la libertad individual no es inherente a la persona, sino que le pertenece a Dios y ese origen determina la posibilidad y el límite de la libertad. El hombre no es libre por sí mismo sino por ser una criatura de Dios. La libertad es una "donación divina".

La libertad está precedida por una ley moral natural de alcance universal. Esa ley es la ley de Dios. Gracias a esa ley se conoce el bien y se evita el mal. El ejercicio de la libertad, por su parte, implica la referencia a esa ley moral que precede y aúna todos los derechos y deberes. ${ }^{34}$ Hay una subordinación de la libertad a Dios. Cuando el hombre en abuso de su libertad persigue fines por sí mismo es instigado por el demonio, desconoce a Dios y a toda su ordenación, afectando a su propia persona y a las relaciones con los demás. Esa libertad es producto del amor 
"desordenado de sí mismo". ${ }^{35}$ La libertad individual, desprovista de moral divina, provoca "desorden".

La relación hombre-mujer es de complementariedad física, psíquica y ontológica. A la "unidad de los dos" Dios les confía la procreación y la vida de la familia como construcción de la historia y finalidad de la trascendencia. Por tanto, no se reconoce la autonomía individual en el matrimonio. El pacto de unión entre hombre y mujer es presentado en la Sagrada Escritura como una imagen del Pacto de Dios con los hombres y, al mismo tiempo, como un servicio a la vida. ${ }^{36} \mathrm{El}$ derecho a la vida, primer derecho enunciado en el Concilio Vaticano II de Pablo VI, desde la concepción hasta su conclusión natural condiciona el ejercicio de cualquier otro derecho y comporta para el catolicismo la ilicitud de toda forma de atentado contra ella, como el aborto provocado y la eutanasia.

Si la vida es el valor y el derecho supremo del orden celestial -porque simboliza la divinidad-y la mujer es la única beneficiada por la naturaleza para consagrarlo, la "mujer procreadora" es tan sagrada como la vida misma porque cada vez que da vida hace "re-nacer a Dios". Por tanto, ese orden, cuando preserva a la "mujer procreadora", preserva su propia existencia, su trascendencia como cosmovisión del mundo.

El cuerpo de las mujeres, a nuestro entender, ha sido provisto para su misión trascendental divina de una "inmunidad natural" (Espósito, 2005), como condición pasiva, que evolucionó luego hacia una "inmunidad inducida". La inmunidad, conceptualmente, es tanto una dispensa como un privilegio. En la combinación de ambos significados es percibida como una excepción a una regla general. Es regla para todos, excepto para quien es inmune. Desde el punto de vista del derecho canónico es algo que interrumpe el circuito social de la donación (Espósito, 2005: 19). Es Dios quien tiene el poder absoluto de "donar" facultades como la libertad humana. El cuerpo de las mujeres es "naturalmente inmune" a la libertad individual porque es fuente de creación divina. Es la lógica del orden natural la que suspende la donación de la libertad del cuerpo para preservarla "inmune" a la naturaleza de la vida. Si Dios le dona a las mujeres la libertad de su cuerpo, como lo hace con el hombre, la cosmovisión del mundo dejaría de ser trascendental para ser finita. La acción de donar la libertad del cuerpo femenino es en sí misma "antinatural" porque crea condiciones para disponer de la decisión de dar o no dar vida. Es decir, es fuente de "desorden".

Por otro lado, la sociedad patriarcal seculariza la "inmunidad natural" y crea una "inmunidad inducida". Para garantizar la preservación del status originario "natural sagrado" se construye una inmunidad que refuerza el dominio maternal pero mediante un "mecanismo de compensación" que desplaza la trascendencia. Se generan las condiciones sociales, políticas, jurídicas y culturales necesarias para prevenir cualquier intento individual de las mujeres de alterar su destino natural.

El derecho a la salud sexual y reproductiva busca compensar el no reconocimiento del derecho a la libertad para decidir. Funciona como una reacción jurídica, no como acción, que impide que otra situación se manifieste como generalidad. El deber "ser madre" ya no proviene, entonces, de un ritual trascendental externo, 
sino de una construcción interna producida por la misma sociedad. Un dato objetivo impuso la realidad: la "inmunidad inducida" institucionaliza "mujeres madres" para que no se extienda la posibilidad de ser "mujeres no madres".

El procedimiento consiste en reproducir de manera "controlada" el mal que se intenta proteger. Para ello no se actúa directamente sobre la libertad de las mujeres para decidir sino indirectamente, mediante lo que se denomina "mecanismo de rodeo" (Espósito, 2005: 50) o de neutralización de la libertad, se controlan sus cuerpos y sus voluntades a partir de la salud. Con esta neutralización de la libertad se protege la maternidad saludable sin afirmar explícitamente la ausencia de libertad para decidir "ser o no ser madre".

El mal "de no querer ser madre" debe enfrentarse como amenaza social, otorgando un "derecho control", punto intermedio entre el bien y el mal: el derecho a la planificación familiar. Así, se excluye indirectamente la atribución de "no ser madre" garantizando la posibilidad de decidir la frecuencia y oportunidad de los nacimientos mediante la anticoncepción reversible; servicios y recursos de salud pública durante el parto y post-parto; información, asesoramiento y consejería. Este derecho que funciona como refugio es sólo condición de posibilidad, no de seguridad, porque como no hay certezas de resultados con las técnicas anticonceptivas reversibles que garantiza la política en cuestión, la mujer que accidentalmente se embaraza está obligada a ser madre.

El mecanismo de "inmunidad inducida" produce, entonces, antinomias de ciudadanía: inclusiones (derechos a la salud sexual y a la salud reproductiva) por exclusión (privación del derecho a la libertad del cuerpo) o, a la inversa, exclusión (del derecho a la libertad del cuerpo) por inclusiones (derechos a la salud sexual y a la salud reproductiva). En síntesis, se protege la salud sexual y la salud reproductiva para poder negar la libertad del cuerpo como derecho de las mujeres. Mediante esa "inmunidad" se constituye a las mujeres para "ser madres" y se las destituye de su opción de "no ser madres", de esa manera se "reconstituye" la vida femenina en esencialmente materna (Espósito, 2005: 15).

El derecho y la política son funcionales al mecanismo inmunitario (Espósito, 2005: 25). Permiten producir en su orden reglas que promueven la "mujer madre" y restringen la opción de "mujer no madre". Pero si bien el derecho es funcional a la construcción inmunitaria, también se ocupa de preservar la libertad a través de los derechos personalísimos. La "inmunidad inducida" expresa, entonces, una construcción compleja de alianzas para "manejar" la protección de un objeto de interés político. Se sacrifica jurídicamente la intensidad del ejercicio de la libertad por la necesidad de preservar la maternidad.

El derecho, la teología y la política encuentran en el procedimiento inmunitario un recurso común a través del cual pueden encauzar sus principales "vectores de sentido", que se entrecruzan en ese papel. En primer lugar, la doctrina católica pretende resguardar el valor "salvífico" de la maternidad y promover un sentido simbólico de dominación al controlar las consecuencias del pecado. En efecto, la "inmunidad" surge como antídoto ante la amenaza de pecado, más que prevenir el "contagio" en sí mismo previene la "generalización" por sus efectos infinitos. 
El "pecado personal" es un acto de alineación que divide al hombre de sí mismo, de Dios y de los demás hombres del mundo que lo rodean. La propagación del pecado a toda la humanidad es la preocupación central del catolicismo, porque en esa generalización se trasmite una naturaleza humana privada de la santidad y de la justicia originales. ${ }^{37}$

La "inmunidad inducida" de la "mujer madre" previene la posibilidad de manifestación generalizada de la voluntad de "no ser madre", que amenaza el cambio en la naturaleza del orden divino. Lo que preocupa es la extensión descontrolada de la amenaza y principalmente cuando proviene de una agresión directa al prójimo. ${ }^{38}$ Estas acciones constituyen "pecado social" por su objeto mismo, atentan contra la justicia en las relaciones entre persona y persona, entre persona y comunidad o entre la comunidad y la persona, no por sus consecuencias (pecado social indirecto).

Por ello, se diferencia el "pecado personal" del "pecado social". El primero es siempre un acto de la persona, porque es un acto de libertad de un hombre particular y no propiamente de un grupo o de una comunidad. Este pecado es objeto de perdón y ayuda de Dios porque no siempre tiene consecuencias sociales y, en caso de que las tenga ("pecado social" indirecto) pueden ser objeto de control. En cambio, el "pecado social", por su objeto mismo, atenta contra el bien común, contra la dignidad humana.

Según la doctrina social de la iglesia el móvil de la mujer que aborta es personal, no hace de su situación una actividad social -es un acto finito- por tanto, si bien rompe la relación con Dios al pecar, puede ser objeto de perdón porque sus consecuencias tienen como límite su persona. ${ }^{39}$ En cambio, quienes colaboran o favorecen abortos (médicos, legisladores, funcionarios públicos, servidores de la salud en general) actúan con un móvil social derivado de la profesión, oficio o gestión, causando un daño generalizado e indeterminado a la comunidad, pudiendo alterar o destruir la naturaleza de la vida. Al ser acciones generalizadas se pone en riesgo la existencia misma de las creencias católicas y surge la necesidad de sanción.

Un segundo vector de sentido de la "inmunidad inducida" es la intencionalidad normativa del derecho que, al mismo tiempo que contiene un ritual, exige el respeto a una prohibición que no se puede violar. La salud sexual y reproductiva prohíbe la anticoncepción irreversible, por tanto, los abortos y la anticoncepción quirúrgica no son permitidos o bien constituyen delitos. Por último, un sentido de "inmediatez" (Espósito, 2005: 28) de la política que hace que la maternidad se sintetice en un preponderante contenido biológico del cuerpo (biopolítica). Para mantener la condición de maternidad hay que "custodiar" el cuerpo. La Ley de Salud Sexual y Procreación Responsable testimonia esta intención. En definitiva, la "inmunidad inducida" da contenido al consensus iuris que sintetiza los intereses del derecho, la política y la religión.

La democracia en Argentina aún no está en condiciones de aceptar la libertad del cuerpo de la mujer como valor ético-político de ciudadanía. Amplía la esfera de reconocimiento y ejercicio de los derechos de la mujer pero, al reservarse el uso y el control social de su libertad plena no le otorga independencia ciudadana. 
Pero esta pulseada de poder nos está indicando movimientos de cambio. Ni el orden social dominante es homogéneo y, por tanto, para sobrevivir tiene que procesar algunos desacuerdos ${ }^{40}$ ni las ciudadanas, aunque precisen la libertad, están dispuestas a rechazar otros reconocimientos posibles de ciudadanía consagrados y aceptados universalmente. ${ }^{41}$ Estos fueron los puntos de llegada -aunque no de partida- al consenso político.

Se ha recorrido hasta la fecha sólo una etapa del conflicto, que es, en el fondo, el "conflicto por la libertad" de las mujeres latinoamericanas. No han sido pocos los avances alcanzados, aunque los resultados no hayan concretado aún la libertad femenina de ciudadanía plena, al menos la sexualidad y la reproducción ya no son más patrimonio oclusivo de las creencias conservadoras, son temas públicos que le pertenecen por derecho a la comunidad política.

\section{Referencias}

* El presente artículo fue elaborado sobre la base de uno de los capítulos de la Tesis Doctoral de la autora, titulada Los derechos de ciudadanía sexuales y reproductivos de la mujer en Argentina, libro en prensa, Buenos Aires, Argentina.

1. El texto se propone respetar el lenguaje no sexista. Sin embargo, a fin de facilitar la lectura, no se utilizaron recursos específicos (“/” o “@”) y se adoptó el masculino sólo en casos inevitables.

2. Seguimos la concepción de ciudadanía de esta autora que desarrollamos más adelante.

3. No obstante en el plano del discurso a nivel internacional entre los objetivos de Desarrollo del Milenio adoptados por la Asamblea General de las Naciones Unidas en el año 2000, se sitúa el problema de la autonomía de la mujer. Estos objetivos intentaron constituirse en prioridades de las agendas gubernamentales de los países de la región. Ver Caminos hacia la equidad de género en América Latina y El Caribe, Novena Conferencia Regional sobre la Mujer en América Latina y El Caribe, CEPAL, México, 2004, pág. 16.

4. Ver arts. 12 y 16 de la Convención. Posteriormente, como resultado de la Conferencia Mundial de Derechos Humanos de Viena de 1993, surge el Programa de Acción que aprobó la Conferencia Internacional sobre Población y Desarrollo celebrada en El Cairo en 1994, y luego la Plataforma de Acción de la Cuarta Conferencia Mundial sobre la Mujer de Beijing de 1995.

5. En el año 2002 se aprueba por Ley Nacional la Política Nacional de Salud Sexual y Procreación Responsable, considerando a los derechos sexuales y reproductivos como facultades del ámbito de la salud y se garantizan para su ejercicio los siguientes beneficios para varones y mujeres: anticoncepción reversible, información y asesoramiento, consejería y educación sexual y reproductiva.

6. Vamos a trabajar los conceptos de "inmunidad natural" e "inmunidad inducida" de Roberto Espósito desarrollados en su obra Inmunitas. Protección y negación de la vida, Ed. Amorrortu, Buenos Aires, 2005 .

7. Resolución Nº 985/2005 del Ministerio de Salud de la Nación, Guía para el mejoramiento de la atención post- aborto en salud pública. Anuncio público efectuado por la Sra. Vice Ministra de Salud y Ambiente de la Nación, Graciela Rosso, en la entrevista realizada por la Revista Debate, titulada "Hay que apuntar a una despenalización progresiva del aborto”, Buenos Aires, 13 de mayo de 2005, pág. 23.

8. Justamente las Políticas de Salud Sexual y Procreación Responsable fueron demandadas por la sociedad argentina, y de toda América Latina, para garantizar condiciones de equidad social en el acceso a estos derechos humanos en contextos de pobreza. Es la inequidad en el acceso y goce de los derechos humanos sexuales y reproductivos el fundamento principal que justifica la responsabilidad política del Estado y la creación de la política pública. No olvidemos que en América Latina, según los últimos datos brindados por la CEPAL (Comisión Económica para América Latina y el Caribe-Naciones Unidas) en el Informe Panorama Social de América Latina 2008, 182 millones de personas son pobres (lo que equivale al 33,2\% de la población total) de esa cifra 71 millones (el 12,9\%) viven en la indigencia, es decir en condiciones de pobreza extrema que les impide garantizar su alimentación diaria para subsis- 
tir. Por otra parte, estudios recientes de la CEPAL que miden la pobreza a nivel individual y no sólo por hogares, ponen en evidencia que de la población pobre, es mayor el porcentaje de mujeres pobres que de varones, tanto en áreas urbanas como rurales e incluso se pueden identificar mujeres pobres en hogares ricos. Para mayor información sobre este aspecto ver Nieves RICO, "Autonomía económica y superación de la pobreza, retos para las políticas de género", División de Desarrollo Social de la CEPAL, Naciones Unidas, Santiago de Chile, 2008.

9. A fin de profundizar en el enfoque adoptado para el análisis se ha trabajado literatura proveniente del campo de la bionomía jurídica (derecho relativo a los cuerpos y a la vida) cuyos aportes resultan sumamente significativos por sus avances teóricos sobre problemas situados en el campo de la reproducción humana y la sexualidad. Fundamentalmente la producción desarrollada toma como acontecimientos empíricos que interpelan al derecho las nuevas tecnologías reproductivas y las prácticas de reproducción asistida. La mayor parte de los trabajos provienen de países europeos (entre ellos España, Italia, Inglaterra, Francia, Suecia) y de Estados Unidos.

10. C. Pateman ha cuestionado incansablemente el pensamiento liberal en sus diferentes obras en aspectos vinculados a la ciudadanía, por ejemplo la dicotomía público/privado. Por otra parte, Seyla Benhabib discute al liberalismo sus concepciones sobre igualdad, universalidad y esfera pública.

11. Ver también de la misma autora Inclusion and Democracy, Oxford University Press, Oxford, 2000 .

12. Así, por ejemplo, se restringió su participación en el ámbito público y se justificó la intervención por exceso del Estado en la esfera doméstica tornando a la familia en un hecho jurídico y político y, al mismo tiempo, normatizando la esfera de la sexualidad.

13. En este punto nuestra argumentación se sostiene en la propuesta de Chantal Mouffe de ciudadanía democrática plural.

14. Tales como la Iglesia Católica y algunos partidos políticos.

15. Coincidimos con Dora Barrancos, cuando señala que fueron más claras las acciones del Estado que intentaron preservar a la mujer en el hogar para garantizar los roles familiares que las que pretendieron promover la natalidad en sí misma, llamadas "pronatalistas".

16. Cabe destacar en este sentido, los aportes provenientes del Centro de Estudios sobre Estado y Sociedad (CEDES) no sólo en términos científicos al producir diagnósticos y avances esclarecedores en torno a la temática sino también en el orden político, al situarse como referente de asesoramiento del Ministerio de Salud de la Nación.

17. A mediados de 1986, se derogó una batería de decretos y leyes restrictivas y, al mismo tiempo, se reconoció por primera vez jurídicamente "el derecho de la pareja a decidir libremente acerca del número y espaciamiento de los hijos".

18. Ley Nacional $\mathrm{N}^{\circ} 26.130$ del $29 / 08 / 06$.

19. El reconocimiento de estos derechos marca el punto de inflexión en el proceso de transformación de la ciudadanía de la mujer, promovido por el movimiento feminista a nivel internacional, basado en una nueva organización política y social de las relaciones de género a través del quiebre de la cultura hegemónica patriarcal. En ese nuevo orden las mujeres no sólo deberían ser reconocidas como sujetos "con derecho a tener derechos" sino que ese status las constituiría en personas con identidad política. El desafío fue "desordenar" el orden patriarcal, católico y conservador, para acelerar un nuevo orden inspirado en la libertad mediante la adquisición de la ciudadanía plena de las mujeres. En Argentina los actores del "desorden" fueron sectores progresistas de la sociedad, pertenecientes a diversos ámbitos públicos (legisladores, jueces, funcionarios, defensorías) y privados (asociaciones profesionales, organizaciones sociales, institutos y centros de investigación, organismos internacionales: CEPAL, PNUD, Banco Mundial, OIT), quienes promovidos por el movimiento feminista llevan adelante estos cambios al instalar el sexo en la esfera pública y desvincularlo de la reproducción, dejando en la voluntad de los sujetos la posibilidad de enlazarlos o no como facultades de ciudadanía. El "orden" católico conservador por su parte, a través del activismo católico que incluyó no sólo a la jerarquía oficial sino también a las prácticas y actitudes de sus fieles desempeñadas a través de sus distintos roles en sociedad, se ocupó de vigilar el sexo, vincularlo siempre a la procreación negando la libertad de decidir, fundado en razones religiosas provenientes de la doctrina social de la Iglesia Católica tal como lo evidencian los 
debates parlamentarios. Se presentan, entonces, dos escenarios de confrontación: los que buscan defender la libertad y los que pretenden combatir la libertad, que dan lugar a un conflicto de carácter político con aspiraciones de transformación social. El catolicismo conservador actúa como actor político y no como actor religioso. El Estado de Derecho no logra garantizar la laicidad de la democracia asegurada por nuestra Constitución Nacional y el conflicto se resuelve mediante un consenso mínimo logrado por la sociedad: la sexualidad y la reproducción serán derechos pero ubicados en el plano de la salud y no en el de la libertad. Este consenso predomina en toda América Latina. Para mayor información ver LEVÍN Silvia, Tesis Doctoral, Op. Cit.

20. La trayectoria de producción legislativa y programática fue acompañada por la movilización permanente del movimiento de mujeres, la toma de posición por parte de líderes de opinión como partidos políticos, representantes de la iglesia católica y otros cultos, y algunos profesionales médicos. No obstante, por primera vez en el país se generó un debate público sobre los derechos sexuales y reproductivos y se reconoció la responsabilidad política del Estado al respecto. Actualmente se debaten en el Congreso de la Nación proyectos de ley de despenalización del aborto y de legalización del aborto.

21. Para un relato cronológico y pormenorizado de los hechos políticos y legislativos sobre la problemática se puede consultar, RAMOS, Silvina y otros, Los médicos frente a la anticoncepción y el aborto, Centro de Estudios sobre Estado y Sociedad, Buenos Aires, 2001.

22. Por ejemplo, y casi elaborando una lista de beneficios, en la legislación argentina que regula la Política de Salud Sexual y Procreación Responsable el Estado se compromete a: proteger la maternidad ...incluyendo información y asesoramiento sobre planificación familiar; eliminar la discriminación contra la mujer en la atención médica a fin de asegurar el acceso a los servicios...que se refieren a la planificación de la familia; garantizar a hombres y mujeres los mismos derechos para decidir libre y responsablemente el número de hijos y el intervalo entre los nacimientos; garantizar a las mujeres el derecho a adoptar decisiones reproductivas en condición de igualdad con los hombres y el derecho a la protección de la salud...en salvaguarda de la función reproductiva; etc.

23. Los desarrollos teóricos provenientes de las ciencias de la vida y del cuerpo en relación con la reproducción asistida que buscan como horizonte explicativo la salud, conciben el derecho a la reproducción como una opción terapéutica frente a la esterilidad concebida como enfermedad. La realidad ha deslegitimado esta argumentación ya que en muchos casos, como se ha demostrado, la intervención no se realiza en el individuo que sufre la supuesta enfermedad. Por ejemplo, son llamativas -advierte la literatura- las crecientes intervenciones de fecundación in vitro que se realizan a las mujeres para resolver la esterilidad masculina o incluso desconociendo el origen de la esterilidad sin importar los riesgos implicados en ese proceso complejo y gravoso. Sólo podría ser aceptada con justicia si la mujer presta conformidad a la intervención, pero en ese caso ya no es el derecho a la protección de la salud el que fundamenta el derecho a la reproducción, sino el de la libre elección como supuesto de la libertad de la persona.

24. Como organismos internacionales y regionales (OPS, OMS, Banco Mundial, BID, CEPAL); Centros de Estudios e Investigación (CEDES, CENEP); asociaciones profesionales vinculadas a la salud (Asociación de Obstetras y Ginecólogos, Asociación Médica, Asociación Nacional de Pediatría); vinculadas al derecho (CELS, Defensoría del Pueblo, asociaciones de abogados); instituciones del Estado en sus distintos niveles de gobierno (Consejo Nacional de la Mujer, Ministerio de Salud y Ambiente de la Nación, Secretarías, etc.).

25. Por ejemplo la posición oficial de la Iglesia Católica en relación con la sexualidad y la reproducción en nuestro país ha incidido en las regulaciones jurídicas y en la aplicación de la normativa existente producida a nivel nacional y provincial, incluso violando el Estado de Derecho. Para un análisis más detallado del problema ver LEVÍN Silvia, Tesis Doctoral "Los alcances de los derechos de ciudadanía sexuales y reproductivos de la mujer en la Argentina actual”, cap. III, en prensa, Buenos Aires, 2009. 26. Para un desarrollo en profundidad de la normativa del Derecho Internacional de los Derechos Humanos referida a esta temática ver LEVÍN Silvia, El conflicto por la libertad. Los derechos sexuales y reproductivos en Argentina en la actualidad, en prensa, Ed. Eudeba, Buenos Aires. Libro elaborado sobre la base de la Tesis Doctoral producida por la autora.

27. No podemos dejar de destacar la importancia que ha tenido la Ley de Cupo Femenino, Ley Malharro, de 1991, que establece la obligación de incluir el 30\% de mujeres en las listas de cargos electivos 
de los partidos políticos - a nivel nacional, provincial y municipal-, que promueve la participación y protagonismo femenino en las instancias de decisión política. Este primer antecedente fue reforzado luego con el Decreto No 1246/2000 del entonces Presidente de la Nación, Dr. Fernando de La Rúa, que amplía la aplicación de la Ley de Cupo N 24.012 y establece la incorporación efectiva de candidatas mujeres al Senado de la Nación. La representación femenina estaba garantizada en ambas Cámaras del Poder Legislativo Nacional. Una de las evidencias de este avance ha sido el fruto de la labor parlamentaria desarrollada por las mujeres en el período 2000/2002 que culmina con la sanción de la Ley Nacional de Salud Sexual y Procreación Responsable.

28. Cuando decimos Iglesia Católica nos referimos a la jerarquía católica.

29. Utilizamos esta expresión para diferenciar diferentes tendencias dentro del catolicismo, por ejemplo sectores católicos progresistas, que han acompañado activamente el proceso de desarrollo de estos derechos y que dentro del movimiento feminista estuvieron representados, en toda América Latina, por la organización Católicas por el Derecho a Decidir.

30. Juan Pablo II: Familiaris Consortio.

31. Santo Domingo, Conclusiones, $\mathrm{N}^{\circ} 214$.

32. Juan Pablo II, Homilía en Santo Domingo.

33. Juan Pablo II, 1993. Carta encíclica Veritatis Splendor.

34. Ibídem.

35. Catecismo de la Iglesia Católica, 1714.

36. Concilio Vaticano II: 1966. Constitución Pastoral Gaudium et Spes.

37. Catecismo de la Iglesia Católica, 404.

38. Por ejemplo, los profesionales de la salud que practican abortos; los legisladores que sancionan leyes que reconocen el derecho a la anticoncepción quirúrgica; los profesionales de la salud que favorecen la eutanasia; los jueces que autorizan abortos mediante sentencias; todos cometen "pecado social".

39. La Comisión Permanente de la Conferencia Episcopal Española, Declaración del 17/06/98, señala: "Nuestro rechazo público no va contra las mujeres tentadas de abortar ante las dificultades de su vida o movidas por un ambiente cada vez más insensible a lo que el aborto es en realidad (...) La Iglesia comprende a las que ya han recurrido a él, pues no duda de que en muchos casos se ha tratado de una decisión dolorosa e incluso dramática. Pero tenemos que denunciar el crimen y, en particular, a quienes lo favorecen por medio de medidas legislativas o administrativas que dejan desprotegida la vida de los inocentes e inducen a los ciudadanos a pensar que el aborto no está tan mal o, incluso, que es un derecho”. En otro documento se establece: “(...) Se ha de dedicar, además, una especial atención pastoral a las mujeres que han padecido o procurado activamente un aborto", Juan Pablo II. Exhortación Apostólica Postsinodal, "Eclesia in América", No 63.

40. Por ejemplo, en la Justicia hay sentencias que reconocen la libertad de la mujer sobre su cuerpo en determinadas ocasiones. Por otra parte, existen declaraciones públicas realizadas por miembros de la Corte Suprema de Justicia de la Nación, Dra. Carmen Argibay, acerca del aborto y la libertad de decidir de la mujer ("Argibay, a favor del aborto". Declaraciones de la Jueza de la Corte. La Nación, 6/08/04; "Argibay defendió su posición a favor de despenalizar el aborto", La Capital, 10/02/04). Tribunales provinciales han autorizado abortos por anencefalia. Otra decisión significativa proviene de la Cámara Nacional de Apelaciones en lo Criminal y Correccional de Capital Federal (La Ley, t.123, p.842) que establece que "no puede instruirse sumario criminal en contra de una mujer que haya causado su propio aborto o consentido en que otro se lo causare, sobre la base de la denuncia efectuada por un profesional del arte de curar que haya conocido el hecho en ejercicio de su profesión o empleo oficial o no, pero sí corresponde hacerlo en todos los casos respecto de sus coautores, instigadores o cómplices". También el dato de ausencia de incriminaciones delictivas por abortos no es menor en una sociedad en que, según datos de especialistas correspondientes al año 2002, se practican quinientos mil abortos anuales. El Poder Ejecutivo, a través del ministro de Salud y Ambiente de la Nación, ha promovido, personalmente, tanto la definición de una política pública en sexualidad y reproducción como la defensa del aborto. Varias provincias argentinas han garantizado políticamente, en esa coyuntura, el derecho a la anticoncepción quirúrgica, ya sea incorporando el beneficio en los programas de salud o mediante leyes específicas sobre el tema, o bien mediante recomendaciones ministeriales. 
41. El movimiento feminista, en general, reivindica los logros aunque sigue luchando políticamente por la ciudadanía plena.

\section{Bibliografía}

H. ARENDT (1987), Los origenes del totalitarismo, Madrid, Editorial Alianza.

D. BARRANCOS (2002), "Derechos sexuales y reproductivos. Notas para la memoria de la promulgación de la Ley de Salud Reproductiva en la Ciudad de Buenos Aires", Mimeo, Buenos Aires, Argentina.

S. BENHABIB (2000), Diversitat cultural, igualtat democrática. La participació politica en l'era de la globalizació, Valencia, Tandem Arguments.

I. BERLIN (1988), Cuatro ensayos sobre la libertad, Madrid, Alianza Editorial.

N. BOBBIO (1993a), "Non mi rassegno alle disiguaglianze", entrevista de G. Bosetti, L'Unità, Roma, 30 de enero.

- (1993b), Igualdad y libertad, Barcelona, Ediciones Paidós.

S. CIFUENTES (1995), Derechos personalísimos, Buenos Aires, Editorial Astrea.

R. A. DAHL (2006), La igualdad política, Buenos Aires, Fondo de Cultura Económica.

R. DAHRENDORF (1990), El conflicto social moderno. Ensayo sobre la política de la libertad, Barcelona, Editorial Mondadori-Grijalbo.

R. ESPOSITO (2005), Inmunitas. Protección y negación de la vida, Buenos Aires, Editorial Amorrortu.

L. FERRAJOLI (2003), Prólogo al libro de Tamar Pitch, Un derecho para dos, Madrid, Editorial Trotta.

S. FLEURY (2002), "Exclusao e cidadania. Teoría da Política Social na América Latina”, mimeo, Río de Janeiro, Brasil.

(2004), "Ciudadanía, exclusión y democracia", en Nueva Sociedad, № 193, Caracas.

N. FRASER (1996), "Gender, Equity and the Welfare State: A Postindustrial Thought", en S. BENHABIB, Democracy and Difference, New Jersey, Princeton Press.

J. HABERMAS (1999), Facticidad y validez, Madrid, Editorial Trotta.

(2004), El futuro de la naturaleza humana, Buenos Aires, Paidós.

A. HELlER y F. FEHER (1989), Políticas de la postmodernidad. Ensayos de crítica cultural, Barcelona, Ediciones Península.

C. JARDIM PINTO (2004), “Ciudadanía y democracia: los aportes de una perspectiva de género", en La democracia en América Latina. Hacia una democracia de ciudadanas y ciudadanos, Contribuciones para el debate, Buenos Aires, PNUD.

C. LEMA AÑON (1999), Reproducción, poder y derecho, Madrid, Editorial Trotta.

Ch. MOUFFE (1999), El retorno de lo politico. Comunidad, ciudadanía, pluralismo, democracia radical, Buenos Aires, Paidós.

C. PATEMAN (1995), El contrato Sexual, Madrid, Editorial Anthropos. (1996), "Críticas feministas a la dicotomía público/privado", en C. CASTELLS (compiladora), AA.VV, Perspectivas feministas en teoría política, Barcelona, Paidós.

PNUD (2004), Informe sobre La Democracia en América Latina. Hacia una democracia de ciudadanas y ciudadanos, Segunda Sección, Programa de las Naciones Unidas para el Desarrollo-PNUD, Buenos Aires, Argentina, septiembre.

J. RAWLS (1996), El liberalismo político, Barcelona, Editorial Crítica.

C. SCHMITT (1984), El concepto de lo político, Buenos Aires, Folios Ediciones.

M. VILLEY (1964), "La genèse du droit subjectif chex Guillaume de Occam", en Archives de Philosophie du Droit, PUF, París, T.9.

I. M. YOUNG (2000), Inclusion and Democracy, Oxford, Oxford University Press.

(1996), "Vida política y diferencia de grupo. Una crítica del ideal de ciudadanía universal", en C. CASTELLS (compiladora), AA.VV, Perspectivas feministas en teoría política, Barcelona, Paidós.

C. YTURBE (1995), "Sobre los derechos fundamentales", en N. RABOTNICOF, A. VELASCO e C. 
YTURBE (Comps.), La tenacidad de la política, México, Universidad Autónoma de México.

G. ZAGREBELSKY (1993), "Senza diritti sociale la società diventa feroce", entrevista de G. Bosetti, $L$ 'Unità, Roma, 6 de febrero.

Recibido: 13/02/09. Aceptado: 07/09/09. 